\title{
FACTOR STRUCTURE AND CUT-OFF SCORES OF THE HOSPITAL ANXIETY AND DEPRESSION SCALE (HADS) IN A CROATIAN SAMPLE OF ADULT PATIENTS SUFFERING FROM ADVANCED CANCER
}

\author{
Maja Miljanović ${ }^{1}$, Joško Sindik $^{2}$, Vibor Milunović ${ }^{3}$, Vesna Kralj Škoc ${ }^{4}$, \\ Marijana Brašs \& Veljko Đorđević ${ }^{5}$ \\ ${ }^{I}$ Department for Quality and Education in Health Care and Social Welfare, \\ Department of Health Technology Assessment, Zagreb, Croatia \\ ${ }^{2}$ Institut for Anthropological Research, Zagreb, Croatia \\ ${ }^{3}$ Clinical Hospital Merkur, Department for Hematology, Zagreb, Croatia \\ ${ }^{4}$ University Hospital Center Zagreb, Department of Oncology, Zagreb, Croatia \\ ${ }^{5}$ University Hospital Center Zagreb, Department of Psychological Medicine, Zagreb, Croatia \\ received: 12.5.2016; \\ revised: 29.9.2016; \\ accepted: 12.10 .2017
}

\section{SUMMARY}

Background: Patients with cancer should be systematically screened for psychological problems at key points in their pathway. Usage of self-report scales for measuring anxiety and depression (such as Hospital Anxiety and Depression scale (HADS)) is a very practical methodfor detecting anxiety and depression. The aim of this research was to determine latent structure, reliability and cutoff scores of HADSin a Croatian sample of adult patients suffering from advanced metastatic cancer.

Subjects and methods: According to inclusion and exclusion criteria, participant were recruited at University Hospital Centre Zagreb (N=46; January 2015) and Clinical Hospital Centre 'Sisters of Mercy' (N=29; April 2015). All participants underwent short structured psychodiagnostic interview, cognitive evaluation (usingMontreal Cognitive Assessment (MoCA) test) and were given HADS.

Results: When using PCA separately for the items of each original scale of HADS, only four items for the component Depression satisfactorily saturate principal component and when using PCA for all the items, only seven items from the original scale satisfactorily saturate unique principal component. Maximum Likelihood extraction method showed that only four items from the original scale satisfactorily saturated the theoretical scales.

Conclusions: The results show that the best solution to use HADS, in defined Croatian population, is as one-dimensional screening instrument (Cronbach's alpha coefficient of internal consistency=0.774) with cut-off score 11/12.

Key words: cancer - depression - anxiety - HADS - factor structure - cut-off scores

\section{INTRODUCTION}

Depression and anxiety are comorbid disabling syndromes that affect an average of $25 \%$ patients with advanced cancer (Lloyd-Williams \& Friedman 2001, Derogatis et al. 1983, Gregurek et al. 2010). The National Institute for Health and Clinical Excellence (NICE) in the United Kingdom are recommending that the patients with cancer should be systematically screened for psychological problems at key points in their pathway (Richardson 2003).

There are many difficulties while diagnosing depression and anxiety. One is that patients often reluctantly reveal their emotional disturbances to their physicians and nurses (Maguire 1985) which leads to unrecognizability of these serious psychological problems and additional suffering. Second difficulty is overlapping of neurovegetative symptoms (especially loss of energy, loss of appetite, and sleep disturbance) of cancer, depression and anxiety (Rayner 2010). Endicott (1984) suggested substituting the psychological symptoms of self-pity, brooding, crying spells, and pessimism for the neurovegetative symptoms that overlap with cancer. Then, many clinicians believe that they themselves would be depressed and/or anxious if they had cancer, so depression and anxiety are sometimes perceived as being "appropriate" in cancer patients (Pirl \& Roth 1999). In addition, there is a problem of lengthy interviews and questionnaires to assess symptoms of depression and anxiety.

Assessment using a structured or semi-structured interview is considered to be the most accurate method for detecting anxiety and depression (Freedland 2002) but this is often impractical on a routine basis as it is time-consuming and prohibitively expensive. Therefore, the use of self-report scales for measuring anxiety and depression is a more practical method in such a frail population. One of screening tool for detection of anxiety and depression in people with physical health problems is Hospital Anxiety and Depression scale (HADS) (Zigmond \& Snaith 1983). It does not include items of a somatic nature, e.g. tiredness, which could be caused by physical disease as much as mood disturbance (Bjelland et al. 2002). HADS consists of a four- 
teen items; seven items relate to anxiety and seven relate to depression. Each item has a 4-point (0-3) Likerttype scale, totaling from 0 to 21 for each subscale, and from 0 to 42 for the combined scales. Higher scores indicate greater anxiety and/or depression. In the original report, the cutoff score was set at 8 for doubtful cases and 11 for definite cases for both anxiety (HADSa) and depression subscales (HADS-d) (Zigmond \& Snaith 1983). However, most subsequent studies have identified the optimal cutoffs for both HADS-a and HADS-d as $\geq 8$, and for HADS-t, $\geq 15$ (Bjelland et al 2002, Herrmann 1997, Ibbotsonet al. 1994).

HADS is quick and easy to administer and this led it being applied extensively in several clinical situations, including oncology care (Castelli et al. 2011, Miklavčić 2008). Some researchers have shown that HADS is best to apply during disease remission or during active care (Pirl \& Roth 1999). The original English version has been translated into in many languages, including Croatian (provided by Mapi Research Trust). Even though the Croatian version of the HADS is commonly used in Croatia, in different populations (eg. Ostojić et al. 2014, Filipovic-Grcic et al. 2010, Vuletić et al. 2011) we could not find any validation studies.

We believe that HADS, because of it shortness and international usage has a potential as screening tool in Croatia on population of patients suffering from advanced cancer. Therefore, the goals of this research is to determine the reliability, construct validity (latent structure) and cut-off scores, applied on a Croatian sample of adult patients suffering from advanced metastatic cancer. Moreover, we will determine the gender differences, to check the exactness of the factorization on the entire sample of participants.

\section{SUBJECTS AND METHODS}

\section{Participants}

Convenient sample comprised of total $\mathrm{N}=81$ patients; $\mathrm{N}=3$ participants were excluded due to unsatisfying cognitive status and $\mathrm{N}=3$ participants refused to participate in the study. Final number of $\mathrm{N}=75$ patients, both gender $(\mathrm{m}=32, \mathrm{f}=43)$ treated at Clinical Hospital Center Zagreb, Oncology Clinic ( $\mathrm{N}=46$, January 2015) and Clinical Hospital Center „Sisters of Mercy“, Institute for Tumors ( $\mathrm{N}=29$, April 2015), was analyzed. Inclusion criteria: cancer grade III/IV, ECOG 0 or 1, treatment without curative intent. Exclusion criteria: metastasis and/or primary malignoma in CNS and brain, unsatisfying cognitive status $(<26$ scores on MoCA test (Montreal Cognitive Assessment)) and presence of acute psychosis, delirium or psychoorganicsyndrome (Table 1).

Due to insufficient data within Croatian National Cancer Registry (Croatian National Institute of Public Health 2015) which is population register (with main purpose to collect valid data on basic epidemiological indicators - incidence, mortality, prevalence and survi- val), sample size for the purpose of this research could not be exactly estimated. Namely, all our five inclusion criteria could not be met to calculate precisely required sample size.

Table 1. Description of the participants $(\mathrm{N}=75)$

\begin{tabular}{|c|c|}
\hline \multicolumn{2}{|l|}{ Hospital } \\
\hline KBCZG f $(\%)$ & $46(61.3)$ \\
\hline KBCSM f $(\%)$ & $29(38.7)$ \\
\hline \multicolumn{2}{|l|}{ Gender } \\
\hline Female f $(\%)$ & $43(57.3)$ \\
\hline Male $f(\%)$ & $32(42.7)$ \\
\hline Age M (SD) & $60.15(10.265)$ \\
\hline \multicolumn{2}{|l|}{ Residence } \\
\hline Countryside $\mathrm{f}(\%)$ & $9(12.0)$ \\
\hline Small town $\mathrm{f}(\%)$ & $3(4.0)$ \\
\hline City & $63(84.0)$ \\
\hline \multicolumn{2}{|l|}{ Marital status } \\
\hline Married f $(\%)$ & $55(73.3)$ \\
\hline Cohabitation $\mathrm{f}(\%)$ & $2(2.7)$ \\
\hline Single $f(\%)$ & $7(9.3)$ \\
\hline Widowed f $(\%)$ & $6(8.0)$ \\
\hline Divorced f $(\%)$ & $5(6.7)$ \\
\hline \multicolumn{2}{|l|}{ Education level } \\
\hline Elementary school f (\%) & $11(14.7)$ \\
\hline Second school f $(\%)$ & $39(52.0)$ \\
\hline Two-three years post second school $\mathrm{f}(\%)$ & 6) $8(10.7)$ \\
\hline University $f(\%)$ & $17(22.7)$ \\
\hline \multicolumn{2}{|l|}{ Employment } \\
\hline Employed and working f (\%) & $4(5.3)$ \\
\hline Employed and on a sick-leave f $(\%)$ & $19(25.3)$ \\
\hline Unemployed f (\%) & $4(5.3)$ \\
\hline Retired f $(\%)$ & $48(64.0)$ \\
\hline \multicolumn{2}{|l|}{ Income } \\
\hline Below average $\mathrm{f}(\%)$ & $37(49.3)$ \\
\hline Average $\mathrm{f}(\%)$ & $29(38.7)$ \\
\hline Above average $\mathrm{f}(\%)$ & $9(12.0)$ \\
\hline VAS pain M (SD) & $2.25(3.5)$ \\
\hline
\end{tabular}

\section{Procedure}

Ethic approval was granted by the Research Ethics Committee Clinical Hospital Centre Zagreb (reference number: 8.1-13/110-2), Research Ethics Committee Clinical Hospital Centre 'Sisters of Mercy' (reference number: EP-4582/15-5) and by Research Ethics Committee School of Medicine, University of Zagreb (reference number:380-59-10106-14-55/143).

According to predefined inclusion and exclusion criteria participants were recruited by oncologist and/or head nurse and then referred to a psychologist. A participant information sheet was provided and written consent obtained from the patients participating in the survey. Data collection started by short psychodiagnostic interview and evaluation of cognitive status of the participant. If participant did not satisfy on the cognitive assessment, the conversation would be continued and participant would not be given to fulfill the questionnaires. The testing procedure was conducted by the patients' bed or in the psychologist room. 


\section{Instruments}

We used short, semistructured, psychodiagnostic interview to detect symptoms of anxiety and depression according to DSM-V (American Psychiatric Association 2013). This method is widely used for research purpose and found to be a valid instrument when interviewer is adequately trained and supervised. The first author of this article is expert user of psychodiagnostic interview. Furthermore, psychodiagnostic interview is "gold standard" for detection any symptoms of psychopathology.

The Montreal Cognitive Assessment (MoCA) test (Nasreddine et al. 2005) is popular cognitive screening tool designed for the detection of Mild Cognitive Impairment (MCI) and mild Alzheimer's disease (AD). It is a one-page 30-point test administered in approximately 10 minutes with cut-off score 26 . The test and administration instructions are freely accessible for clinicians at www.mocatest.org. The MoCA assesses several cognitive domains: memory recall, visuospatial abilities, attention, concentration and working memory. We used Croatian version of the test with the approval from Dr Ziad Nasreddine, Neurologist, $\mathrm{MoCA}^{\odot}$ Copyright Owner.

We used Croatian version of the HADS with the permission of GL Assessment, Mapi Research Trust. Mapi Linguistic Validation translated the HADS into Croatian but do not have information about psychometric validation. Systematic review conducted in 2012 (Cosco 2011) pointed out that previous findings on the latent structure of the HADS have been largely inconsistent. Although some factor analytic studies (Moorey et al. 1991) supported a two-factor structure (anxiety and depression), other studies (Dunbar et al. 2000) found a superior fit for a three-factor construct. In metaanalysis by Norton and colleagues (2013) was concluded that due to the presence of a strong general factor, the HADS does not provide good separation between symptoms of anxiety and depression; author recommend HADS usage as a measure of general distress.

\section{Statistical analysis}

In attempts to adjust HADS in goal Croatian population, four data analysis strategies for reducing the influence of the bias in cross-cultural research (Sindik 2013) are used. In the first analysis, we have analyzed only reliabilities (without exploring latent dimensions) of all the items in the original scale, separately for the items that belong to each of the original scales of measuring instrument HADS (depression, anxiety). Second analysis is performed using Principal Component Analysis (PCA), separately for the items of each original scale of HADS, anxiety and depression, obtaining two one-component solutions (one for the depression and one for the anxiety). Third analysis is performed using Principal Component Analysis (onecomponent solution), for all the items of each original scale of HADS. Finally, the last analysis is performed using Maximum Likelihood extraction method with
Promax rotation and two-component solution, for all the items of original scale of HADS.

In all factor and component analyses (second, third and fourth), minimal saturation of 0.35 between factor (component) and each item is fixed, while Scree Plot is used to indicate the best number of factors, needed to explain the total variance. In fourth analysis, number of factors was fixed on two, while the criterion of interpretability was used, to keep only the items which describe depression in one factor, and the items that describe the anxiety in other factor. After obtaining final factor solutions, Cronbach's alpha coefficients of internal consistency are calculated.

Second step was to determine possible cut off scores using Receiver Operating Characteristic (ROC) curve. Rational for ROC analysis is rating diagnostic test results (HADS) versus a gold standard (psychodiagnostic interview). We used HADS scores to predict dichotomous outcome is, or is not, patient emotionally disturbed. Decision about the optimal value is based on the tradeoff between sensitivity and specificity (which were equally important in this research).

For performing all the statistical analyses, $\mathrm{R}$ software (R Project for Statistical Computing) was used, while the significances were commented on the level of $p<0.05$.

\section{RESULTS}

Our goal was to determine underlying factors structure of HADS.

In the first analysis, when analyzing only reliabilities' of all the items of the original scales of measuring instrument HADS, Cronbach's alpha coefficient of internal consistency for Anxiety scale (7 items) was 0.746 , while Cronbach's alpha coefficient for Depression scale was 0.587 ( 7 items). Cronbach's alpha coefficient of internal consistency for total score (all items from "Anxiety" and "Depression") is 0.774 .

Second analysis is performed using PCA onecomponent solution, separately for the items of each original scale of HADS, anxiety and depression (Table 2). All items for the component Anxiety satisfactorily saturate principal component, which explained about $40 \%$ of the total variance in all seven items. The highest mean is found for the first item (I feel tense or wound up). Only four items for the component Depression satisfactorily saturate principal component, which explained about $65 \%$ of the total variance in these four items. The highest mean is found for the eighth item (I feel as if I am slowed down).

Third solution is performed using Principal Component Analysis (one-component solution), for all the items of each original scale of HADS (Table 3). Only seven items from the original scale satisfactorily saturate unique principal component, that explains about $49 \%$ of the total variance in these seven items. Four items originally depends to the subscale of depression, while three items are related to the anxiety. 
Table 2. Principal Components Analysis (PCA) performed separately for the items of each original scale of HADS, anxiety and depression

\begin{tabular}{|c|c|c|c|c|}
\hline Items & $\begin{array}{c}\text { Component } \\
\text { Anxiety }\end{array}$ & Communalities & Mean & Std. Dev. \\
\hline 1. I feel tense or wound up & 0.763 & 0.583 & 1.53 & 1.329 \\
\hline 3. I get a sort of frightened feeling as if something bad is about to happen & 0.633 & 0.401 & 1.11 & 1.300 \\
\hline 5. Worrying thoughts go through my mind & 0.652 & 0.425 & 1.01 & 1.180 \\
\hline 7. I can sit at ease and feel relaxed & 0.493 & 0.244 & 0.35 & 0.744 \\
\hline 9. I get a sort of frightened feeling like butterflies in the stomach & 0.405 & 0.164 & 0.35 & 0.846 \\
\hline 11. I feel restless and have to be on the move & 0.652 & 0.426 & 1.21 & 1.254 \\
\hline 13. I get sudden feelings of panic & 0.747 & 0.558 & 0.68 & 1.164 \\
\hline Kaiser-Meyer-Olkin & 0.737 & & & \\
\hline Bartlett's Test of Sphericity $(\mathrm{df}=21)$ & $124.032 * * *$ & & & \\
\hline Eigenvalue / Variance explained (\%) & 2.800 & $40.004 \%$ & & \\
\hline Reliability (Cronbach's $\alpha$ ) & 0.746 & & & \\
\hline Items & $\begin{array}{l}\text { Component } \\
\text { Depression }\end{array}$ & Communalities & Mean & Std. Dev. \\
\hline 2. I still enjoy the things I used to enjoy & 0.722 & 0.522 & 0.37 & 0.673 \\
\hline 4. I can laugh and see the funny side of things & 0.848 & 0.720 & 0.35 & 0.688 \\
\hline 6. I feel cheerful & - & - & 1.21 & 1.349 \\
\hline 8. I feel as if I am slowed down & - & - & 1.92 & 1.160 \\
\hline 10. I have lost interest in my appearance & - & - & 1.04 & 1.267 \\
\hline 12. I look forward with enjoyment to things & 0.877 & 0.769 & 0.36 & 0.680 \\
\hline 14. I can enjoy a good book or radio or TV programme & 0.758 & 0.574 & 0.24 & 0.694 \\
\hline Kaiser-Meyer-Olkin & 0.755 & & & \\
\hline Bartlett's Test of Sphericity $(\mathrm{df}=6)$ & $107.098 * * *$ & & & \\
\hline Eigenvalue / Variance explained (\%) & 2.585 & $64.623 \%$ & & \\
\hline Reliability (Cronbach's $\alpha$ ) & 0.815 & & & \\
\hline
\end{tabular}

Legend: Chi square significant at $\mathrm{p}<0.001$

Table 3. Principal Components Analysis (PCA - one-component solution) performed for all the items of each original scale of HADS

\begin{tabular}{lcc}
\hline Items & $\begin{array}{c}\text { Unique } \\
\text { Component }\end{array}$ & Communalities \\
\hline 2. I still enjoy the things I used to enjoy & 0.680 & 0.463 \\
4. I can laugh and see the funny side of things & 0.831 & 0.690 \\
5. Worrying thoughts go through my mind & 0.422 & 0.178 \\
7. I can sit at ease and feel relaxed & 0.800 & 0.641 \\
9. I get a sort of frightened feeling like butterflies in the stomach & 0.605 & 0.367 \\
12. I look forward with enjoyment to things & 0.829 & 0.687 \\
14. I can enjoy a good book or radio or TV programme & 0.686 & 0.471 \\
Kaiser-Meyer-Olkin & 0.816 & \\
Bartlett's Test of Sphericity (df=36) & $83.853 * * *$ & $49.433 \%$ \\
Eigenvalue / Variance explained $(\%)$ & 3.495 & 0.791 \\
Reliability (Cronbach's $\alpha$ ) & & \\
\hline
\end{tabular}

Legend: Chi square significant at $\mathrm{p}<0.001$

Scree Plot (Figure 1) indicate a convenience of onecomponent solution, but also emphasize the possibility of determining satisfactorily two-factor solution (eigenvalue higher than 1).

Fourth solution is performed using Maximum Likelihood extraction method with Promax rotation and two-component solution, for all the items of each original scale of HADS (Table 4). The correlations between two factors (anxiety and depression), in the final solution was 0.078 (non-significant). Only four items from the original scale satisfactorily saturate the factor (subscale) of depression, same as the factor (subscale) of anxiety. Both factors together explain about $49 \%$ of the total variance in all eight items in the final solution.

Scree Plot (Figure 2) clearly indicate a convenience of two-factor solution (eigenvalue higher than 1) with remaining eight items.

For factor analysis justification, we have explored gender differences considering gained component solutions. Calculations show us that there are no statistically significant sample gender differences (Table 5). 
Table 4. Principal Components Analysis (PCA - one-component solution) performed for all the items of each original scale of HADS

\begin{tabular}{|c|c|c|c|}
\hline Items & $\begin{array}{c}\text { Factor } \\
\text { Depression }\end{array}$ & $\begin{array}{c}\text { Factor } \\
\text { Anxiety }\end{array}$ & Communalities \\
\hline 1. I feel tense or wound up & & 0.736 & 0.551 \\
\hline 2. I still enjoy the things I used to enjoy & 0.620 & & 0.401 \\
\hline 3. I get a sort of frightened feeling as if something bad is about to happen & & 0.631 & 0.398 \\
\hline 4. I can laugh and see the funny side of things & 0.803 & & 0.654 \\
\hline 5. Worrying thoughts go through my mind & & 0.515 & 0.319 \\
\hline 12. I look forward with enjoyment to things & 0.847 & & 0.722 \\
\hline 13. I get sudden feelings of panic & & 0.660 & 0.438 \\
\hline 14. I can enjoy a good book or radio or TV programme & 0.653 & & 0.432 \\
\hline Kaiser-Meyer-Olkin & 0.740 & & \\
\hline Bartlett's Test of Sphericity $(\mathrm{df}=28)$ & $174.699 * * *$ & & \\
\hline Eigenvalue & 2.261 & 1.655 & \\
\hline Variance explained (\%) & $28.264 \%$ & $20.690 \%$ & \\
\hline Reliability (Cronbach's $\alpha$ ) & 0.815 & 0.725 & \\
\hline
\end{tabular}

Legend: Chi square significant at $\mathrm{p}<0.001$

Table 5. Gender differences regarding obtained factor solutions

\begin{tabular}{|c|c|c|c|c|c|c|c|}
\hline Factor solution & Structure & Difference & Sum of Squares & $\mathrm{df}$ & Mean Square & $\mathrm{F}$ & Sig \\
\hline \multirow{6}{*}{ Second } & \multirow{3}{*}{ Anxiety } & Between Groups & 24.671 & 1 & 24.671 & \multirow{3}{*}{1.132} & \multirow{3}{*}{0.291} \\
\hline & & Within Groups & 1569.815 & 72 & \multirow{2}{*}{21.803} & & \\
\hline & & Total & 1594.486 & 73 & & & \\
\hline & \multirow{3}{*}{ Depression } & Between Groups & 0.619 & 1 & 0.619 & \multirow{3}{*}{0.046} & \multirow{3}{*}{0.831} \\
\hline & & Within Groups & 988.223 & 73 & \multirow{2}{*}{13.537} & & \\
\hline & & Total & 988.842 & 74 & & & \\
\hline \multirow{3}{*}{ Third } & \multirow{3}{*}{$\begin{array}{l}\text { Anxiety \& } \\
\text { depression }\end{array}$} & Between Groups & 21.147 & 1 & 21.147 & \multirow{3}{*}{1.514} & \multirow{3}{*}{0.222} \\
\hline & & Within Groups & 1019.686 & 73 & \multirow{2}{*}{13.968} & & \\
\hline & & Total & 1040.832 & 74 & & & \\
\hline \multirow{6}{*}{ Fourth } & \multirow{3}{*}{ Anxiety } & Between Groups & 0.733 & 1 & 0.733 & \multirow{3}{*}{0.053} & \multirow{3}{*}{0.818} \\
\hline & & Within Groups & 1005.934 & 73 & \multirow{2}{*}{13.780} & & \\
\hline & & Total & 1006.667 & 74 & & & \\
\hline & \multirow{3}{*}{ Depression } & Between Groups & 3.562 & 1 & 3.562 & \multirow{3}{*}{0.738} & \multirow{3}{*}{0.393} \\
\hline & & Within Groups & 352.392 & 73 & \multirow{2}{*}{4.827} & & \\
\hline & & Total & 355.954 & 74 & & & \\
\hline
\end{tabular}

Legend: factors defined by the items in factor solutions:second (Table 2), third (Table 3) and fourth (Table 4)

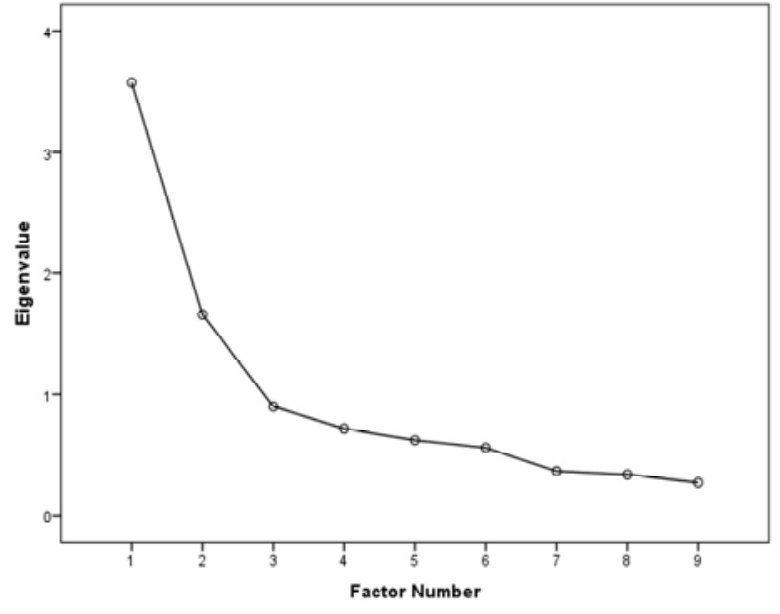

Figure 1. Scree plot for final seven items included in one-component solution after iterations of Principal Component Analysis

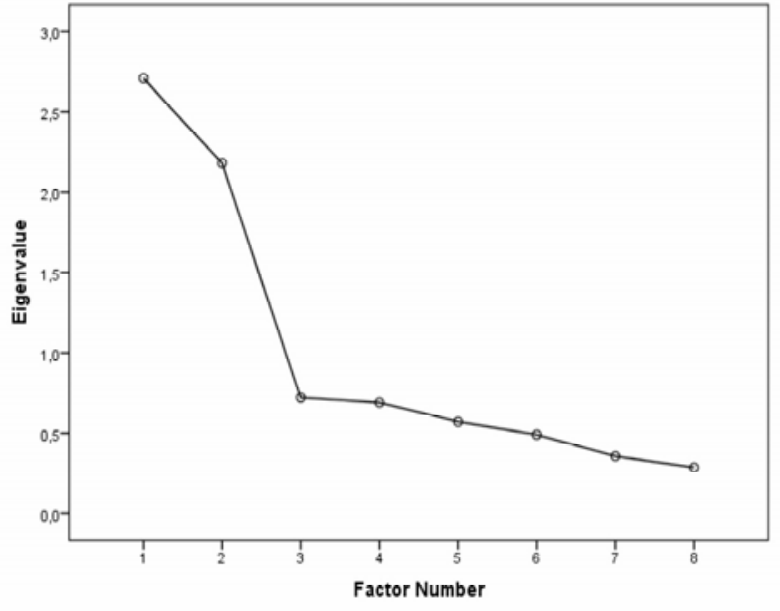

Figure 2. Scree plot for final eight items included in two-component solution after iteration of Maximum Likelihood extraction method with Promax rotation 
Table 6. Coordinates of the Curve

\begin{tabular}{|c|c|c|}
\hline $\begin{array}{l}\text { Positive if Greater } \\
\text { Than or Equal To }\end{array}$ & Sensitivity & 1 - Specificity \\
\hline-1.0000 & 1.000 & 1.000 \\
\hline 0.5000 & 1.000 & 0.947 \\
\hline 1.5000 & 1.000 & 0.912 \\
\hline 2.5000 & 0.944 & 0.877 \\
\hline 3.5000 & 0.944 & 0.789 \\
\hline 4.5000 & 0.944 & 0.772 \\
\hline 5.5000 & 0.944 & 0.719 \\
\hline 6.5000 & 0.889 & 0.649 \\
\hline 7.5000 & 0.889 & 0.526 \\
\hline 8.5000 & 0.833 & 0.526 \\
\hline 9.5000 & 0.833 & 0.491 \\
\hline 10.5000 & 0.778 & 0.439 \\
\hline 11.1550 & 0.778 & 0.386 \\
\hline 11.6550 & 0.778 & 0.368 \\
\hline 12.5000 & 0.667 & 0.351 \\
\hline 13.5000 & 0.611 & 0.298 \\
\hline 14.5000 & 0.611 & 0.263 \\
\hline 15.5000 & 0.611 & 0.193 \\
\hline 16.3167 & 0.556 & 0.158 \\
\hline 16.8167 & 0.500 & 0.158 \\
\hline 17.5000 & 0.444 & 0.105 \\
\hline 18.3514 & 0.333 & 0.070 \\
\hline 19.3514 & 0.333 & 0.053 \\
\hline 20.5000 & 0.278 & 0.035 \\
\hline 21.5000 & 0.278 & 0.018 \\
\hline 23.0000 & 0.222 & 0.000 \\
\hline 26.5000 & 0.167 & 0.000 \\
\hline 29.5000 & 0.111 & 0.000 \\
\hline 31.5000 & 0.056 & 0.000 \\
\hline 34.0000 & 0.000 & 0.000 \\
\hline
\end{tabular}

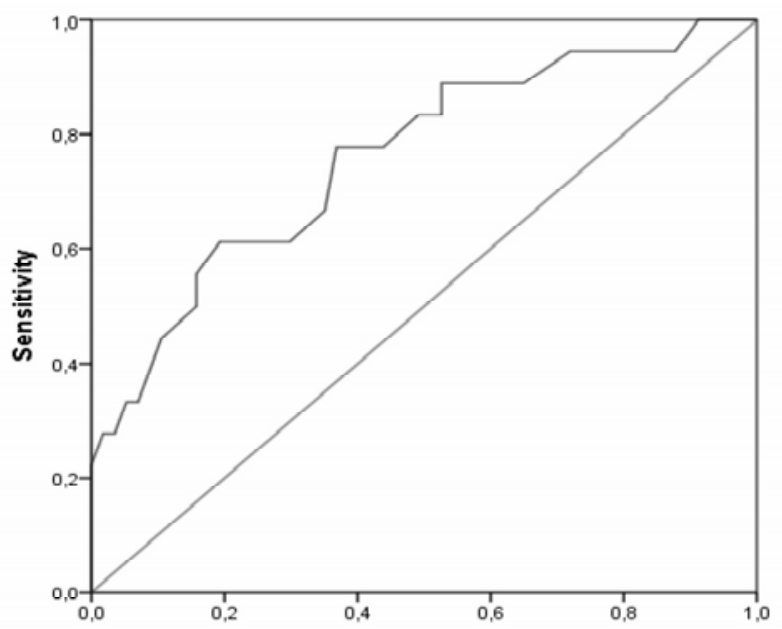

Figure 3. ROC curve of HADS total score

To decide whether HADS total score is good predictor of dichotomous outcome "is/not emotionally disturbed", or to decide about trade-off between sensitivity and specificity of HADS total score cut-off value, we used Receiver Operating Characteristics (ROC) Curve (Figure 3).
Our ROC curve is statistically significant $(\mathrm{p}=0.001$; $95 \%$ CI $0.629-0.893$ ). Area under the curve is 0.761 (Std. Error $=0.067$ ) according to which we can say that HADS total score has some use as diagnostic tool but is not completely reliable or accurate.

The point of the curve which is the closest to the "upper left corner", or has the best balance between sensitivity (0.8) and 1-specificity (0.2), is value of $11 / 12$ (Table 6).

\section{DISCUSSION}

Advanced cancer is a frightening condition often accompanied by difficult losses (of organ functions, social roles, physical strength etc.) which can possibly result in severe mental distress like anxiety and depression. As a result, all cancer patients should be triaged using screening instruments. In this study, we aimed to identify optimal factor structure and cutoff scores for one of the most commonly used screening tools for mental distress in oncology, the HADS.

Our results suggest that the original bi-dimensional measurement model of HADSdoes not display an adequacy of fit to our data. Results can be viewed as not supporting for 'standard' construct validity of HADS (with all the items included in the original scale).

In firs analysis we have revealed that the reliability type internal consistency for Anxiety scale is moderate high (0.746), while Cronbach's alpha coefficient for Depression scale was low (0.587). In case when we use all items of the original scale(s) of HADS, Cronbach's alpha coefficient is "the highest" (0.774).

When PCA is performed separately for the items of each original scale of HADS, anxiety and depression, reliability for the scale of Depression increased and became high (but with reduced number of items that saturate this principal component). In one-component solution only seven items remained in final iteration, three that belong to the original scale of Anxiety and four that belong to the original scale of Depression, with high reliability. Finally, only eight items remained in final iteration of two-factorial solution (four that belong to the original scale of Anxiety and four to the original scale of Depression). The reliability for the scale of Depression is high, while the reliability for scale of Anxiety is moderately high.

The magnitude of factors ,anxiety“ and „,depression" intercorrelation in the present study was found to be substantial indicating that the severity of depressive and anxious symptoms in fact do covary at large. However, the correlation between factors ,anxiety“ and „depression“ depends about type of factor rotation. In two solutions for which we have calculated the correlation, type of factor rotation did not have an decisive influence on these correlations (rotation in Table 4 is not orthogonal, while in Table 2 the rotation of principal components is not performed). 
Results are similar to the results of studies (eg. Carroll et al. 1993) conducted on population of patients suffering from advanced cancer. They reported high correlation between both anxiety and depression subscale scores, suggesting that HADS performs differently in patients with advanced cancer than those with early or stable disease. The degree of overlap between symptoms of anxiety and depression across HADS items iscalling into question the ability of the scale to differentiate between these disorders. While the disparate subscales of the HADS are intended to measure mutually exclusive levels of anxiety (HADSA) and depression (HADS-D) one systematic review of the latent structure of the HADS does not support the traditional anxiety-depression bi-dimensional structure. Zigmond \& Snaith (1983) assume that a strong association between the subscales would indicate that "they could be considered much the same thing, for example, emotional disturbance".

Combining the best levels of sensitivity (77\%) and specificity $(70 \%)$ we decided that the optimal cutoff point of HADS total score, for our sample, is 11/12. Creators of the questionnaire (Zigmond \& Snaith 1983) recommend cut-off value of $\geq 16$ (for HADS total score), but some other researchers (Morse et al. 2005) suggest that lower thresholds should be used for cancer patients ( $\geq 13$ for HADS total score).

We would welcome the day when, as part of standard care, all cancer patients receive a psychosocial screening instrument, the results of which would be perused by the appropriate clinician.

\section{Limitation}

Firstly, the sample size $(\mathrm{N}=75)$ was quite small. Recruiting patients who are terminally ill is very difficult. Many patients are too frail to undergo any form of extensive interviewing and/or psychological testing. Secondly, this was a convenience sample, without any control group. This self-selection bias reduces the generalizability of the results, since the individuals who presented themselves to the psychologist, may have had different rates of psychological distress. Furthermore, HADS is able to screen mental distress, but we cannot conclude from our data that it is sufficient for identifying the need for psychosocial support. This need not only depends on psychological comorbidity, but also on poor social support, and the patients' desire for such support as well.

To overcome these limitations, a large-scale cohort study (performed on larger and more representative samples) should be done, in which all the patients are recruited and screened for depression.

\section{CONCLUSION}

The findings of the present study suggest that Hospital Anxiety and Depression scale (HADS) can be used as one-dimensional screening tool for emotional disturbance with cut-off score $11 / 12$ on patients suffering from advanced cancer. HADScould be used in oncoloy wards to assess depression and anxiety, helping clinicians identify patients who needspecial psychiatric or psychological care.

\section{Acknowledgements:}

This research is part of project "Palliative care in Croatia: attitudes and need medical personnel and patients suffering from advanced cancer" coordinated by Center for Palliative Medicine, Medical Ethics and Communication Skills (CEPAMET) and funded by Adris Foundation. First author would like to appreciate the cooperation and coordination of the hospital director and all the staff of University Hospital Centre Zagreb, Department of Oncology and Clinical Hospital Centre "Sisters of Mercy“, Clinic for Tumors, including all the participants of the study.

\section{Conflict of interest: None to declare.}

\section{Contribution of individual authors:}

Maja Miljanović: design of the study, literature searches and analyses, statistical analyses, interpretation of data, first draft and revising it critically for important intellectual content; approval of the final version;

Joško Sindik: statistical analyses, interpretation of data,first draft and revising it critically for important intellectual content;

Vibor Milunović: literature searches and analyses, first draft and revising it critically for important intellectual content;

Vesna Kralj Škoc: literature searches and analyses, recruiting participants, first draft and revising it critically for important intellectual content;

Marijana Braš: first draft and revising it critically for important intellectual content; approval of the final version;

Veljko Đorđević: first draft and revising it critically for important intellectual content; approval of the final version;

\section{References}

1. American Psychiatric Association: Diagnostic and statistical manual of mental disorders (5th ed.). American Psychiatric Publishing, Arlington, 2013.

2. Bjelland I, Dahl A, Haug T, Neckelmann D: The validity of the Hospital Anxiety and Depression Scale. An updated literature review. J Psychosom Res 2002; 52:69-77.

3. Carroll B, Kathol $R$, Noyes $R$, Wald T, Clamon $G$ : Screening for depression and anxiety in cancer patients using the Hospital Anxiety and Depression Scale. Gen Hosp Psychiatry 1993;15:69-74.

4. Castelli L, Binaschi L, Caldera P, Mussa A, Torta R: Fast screening of depression in cancer patients: the 
effectiveness of the HADS. Eur $J$ Cancer Care 2011; 20:528-33.

5. Cosco T, Doyle F, Ward M, McGee H: Latent structure of the Hospital Anxiety and Depression Scale: a 10-year systematic review. J Psychosom Res 2012; 72:180-4.

6. Croatian National Institute of Public Health. Cancer incidence in Croatia 2013. Bulletin No 38. Croatian National Institute of Public Health, Zagreb, 2015.

7. Dunbar M, Ford G, Hunt K, Der G: A confirmatory factor analysis of the Hospital Anxiety and Depression scale: comparing empirically and theoretically derived structures. Br J Clin Psychol 2000; 39:79-94.

8. Derogatis LR, Morrow GR, Fetting J, Penman D, Piasetsky S, Schmale AM et al.: The prevalence of psychiatric disorders among cancer patients. Jama 1983; 249:751-7.

9. Endicott J: Measurement of depression in patients with cancer. Cancer 1984; 53:2243-9.

10. Filipovic-Grcic IF, Tonkovic DT, Grubisin JG, Perić MP, Majeric Kogler VM: Hospital anxiety depression scale in our surgical ICU. Crit Care 2010;14:499.

11. Gregurek R, Bras M, Dordević V, Ratković AS, Brajković L: Psychological problems of patients with cancer. Psychiatr Danub 2010; 22:227-30.

12. Ibbotson T, Maguire P, Selby P, Priestman T, Wallace L: Screening for anxiety and depression in cancer patients: the effects of disease and treatment. Eur J Cancer 1994; 30:37-40.

13. Maguire P: Improving the detection of psychiatric problems in cancer patients. Soc Sci Med 1985; 20:819-23.

14. Miklavcic IV, Snoj Z, Mlakar J, Pregelj P: Validation of the Slovenian version of Hospital Anxiety and Depression Scale in female cancer patients. Psychiatr Danub 2008, 20:148-52.

15. Moorey S, Greer S, Watson M, Gorman C, Rowden L, Tunmore R: The factor structure and factor stability of the hospital anxiety and depression scale in patients with cancer. Br J Psychiatry 1991; 158:255-9.

16. Norton S, Cosco T, Doyle F, Done J, Sacker A: The Hospital Anxiety and Depression Scale: a meta confirmatory factor analysis. J Psychosom Res 2013; 74:74-81.

17. Ostojić D, Vidović D, Baceković A, Brecić P, Jukić V: Prevalence of anxiety and depression in caregivers of
Alzeheimer's dementia patients. Acta Clin Croat 2014; 53:17-21.

18. Richardson A: Cancer care. Improving supportive and palliative care for adults with cancer. Nurs Times 2003; 99:49.

19. Herrmann C: International experiences with the Hospital Anxiety and Depression Scale-a review of validation data and clinical results. J Psychosom Res 1997; 42:17-41.

20. Lloyd-Williams M, Friedman T: Depression in palliative care patients-a prospective study. Eur $J$ Cancer Care 2001; 10:270-4.

21. Freedland KE, Skala JA, Carney RM., Raczynski JM, Taylor CB, Mendes de Leon CF: The Depression Interview and Structured Hamilton (DISH): rationale, development, characteristics, and clinical validity. Psychosom Med 2002; 64:897-905.

22. Morse R, Kendell K, Barton S: Screening for depression in people with cancer: the accuracy of the hospital anxiety and depression scale in patients with breast cancer. Health Qual Life Outcomes 2005; 3:41.

23. Nasreddine ZS, Phillips NA, Bédirian V, Charbonneau S, Whitehead V, Collin I et al.: The Montreal Cognitive Assessment (MoCA): A Brief Screening Tool for Mild Cognitive Impairment. J Am Geriatr Soc 2005; 53:695-9.

24. Pirl W, Roth A: Diagnosis and treatment of depression in cancer patients. Oncology 1999; 13:1293-1301.

25. Rayner L, Price A, Evans A, Valsraj K, Hotopf $M$, Higginson I: Antidepressants for the treatment of depression in palliative care: systematic review and metaanalysis. Palliative Medicine 2011; 25:36-51.

26. Sindik J: Data Analysis Strategies for Reducing the Influence of the Bias in Cross-Cultural Research. Coll Antropol 2012; 36:31-7.

27. Singer S, Kuhnt S, Götze H, Hauss J, Hinz A, Liebmann A et al.: Hospital anxiety and depression scale cutoff scores for cancer patients in acute care. Br J Cancer 2009; 100:908-12.

28. Vuletić V, Ležaić Ž, Morović S: Post-stroke fatigue. Acta Clin Croat 2011; 50:341-4.

29. Zigmond A, Snaith R: The hospital anxiety and depression scale. Acta Psychiatr Scand 1983; 67:361-70.

Correspondence:

Maja Miljanovic, MA

Agency for Quality and Education in Health Care and Social Welfare

Planinska 13, 10000 Zagreb, Croatia

E-mail:maya.boban@gmail.com 